\title{
GESTÃO DO CAPITAL RELACIONAL NA LÓGICA DOMINANTE DE SERVIÇO EM EMPRESAS INTENSIVAS EM CONHECIMENTO
}

\author{
Cinthya Mônica da Silva Zanuzzi'; \\ Lídia Neumann Potrich²; \\ Patsy Geraldine Balconi Mandelli ${ }^{3}$; \\ Paulo Maurício Selig'; \\ Gregório Varvakis 5
}

\begin{abstract}
In SDL (Service Dominant Logic), service is characterized as the central objective of economic exchange and its value arises from the interactions of the actors, who activate and integrate their skills and abilities, in the co-creation process. Relational Capital (CR), on the other hand, refers to the knowledge existing in the company and customer relationship, and its relevant value. Thus, the objective of this study is understand how the management of the CR can boost the SDL of knowledge-intensive companies. Therefore, qualitative research was adopted as a methodological approach, through the study of multiple cases. Data collection took place through semi-structured interviews, conducted with 6 CEOs of the companies. The results demonstrate that the management of the CR can contribute to the co-creation value of the service, in the perspective of the SDL.
\end{abstract}

Keywords: Servive Dominant Logic; Relational Capital; Value Creation; Co-creation

Resumo: Na SDL (Service Dominant Logic) o serviço é caracterizado como objetivo central da troca econômica e o seu valor nasce das interações dos atores, que ativam e integram suas competências e capacidades, no processo de cocriação. Já o Capital Relacional (CR) diz respeito ao conhecimento existente na relação empresa e cliente, e seu valor relevante. Dessa forma, o objetivo deste estudo é compreender como a gestão do CR pode impulsionar a SDL, de empresas intensivas em conhecimentos. Para tanto, adotou-se como abordagem metodológica a pesquisa qualitativa, através do estudo de casos múltiplo. A coleta de dados aconteceu por meio de entrevistas semiestruturadas, realizadas com 6 CEOs das empresas. Os resultados demonstram que as a gestão do CR pode contribuir para a cocriação de valor do serviço, na perpectiva da SDL.

Palavras-chave: Lógica Dominante de Serviço; Capital Relacional; Criação de valor; Cocriação.

\footnotetext{
${ }^{1}$ Engenharia e Gestão do Conhecimento - Universidade Ferderal de Santa Catarina (UFSC) Florianópolis - Brasil. Correo electrónico: cinthyamsz01@gmail.com

${ }^{2}$ Engenharia e Gestão do Conhecimento - Universidade Ferderal de Santa Catarina (UFSC) Florianópolis - Brasil. Correo electrónico: lidia.potrich@gmail.com

${ }^{3}$ Engenharia e Gestão do Conhecimento - Universidade Ferderal de Santa Catarina (UFSC) Florianópolis - Brasil. Correo electrónico: patsymandedlli@gmail.com

${ }^{4}$ Engenharia e Gestão do Conhecimento - Universidade Ferderal de Santa Catarina (UFSC) Florianópolis - Brasil. Correo electrónico: pauloselig@gmail.com

${ }^{5}$ Engenharia e Gestão do Conhecimento - Universidade Ferderal de Santa Catarina (UFSC) Florianópolis - Brasil. Correo electrónico: g.varvakis@ufsc.br
}

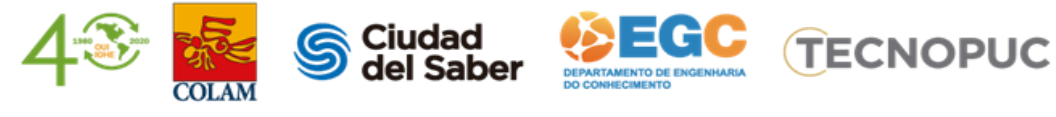




\section{INTRODUÇÃO}

O paradigma emergente da lógica dominante de serviço pode ser considerado como uma evolução da visão tradicional sobre onde e como o valor é criado, apontando para uma necessidade cada vez maior de compreensão sobre a complexidade das relações existentes em um contexto mercadológico em constante mutação (Lusch \& Vargo, 2014). Para Brambilla e Damacena (2010) apesar dos prêmios e reconhecimento da obra original da lógica de serviço de Lusch e Vargo do ano de 2004, refinos foram desenvolvidos acerca desta orientação da 'nova' lógica de 'Service Dominant Logic' (SDL), culminando em novos trabalhos dos próprios autores e de outros estudiosos. Na SDL, o serviço é caracterizado como objetivo central da troca econômica, e estabelece uma fundamentação teórica para a compreensão de como a empresa, o cliente e outras partes interessadas podem cocriar valores por meio das interações dos serviços entre si.

Kon (2004) ao citar, Josef Schumpeter (1983), faz referencia a apresentação de uma abordagem nova das características dos produtos, afirmando que a produção nada cria no sentido físico, considerando tanto tecnologicamente quanto economicamente. Apenas influencia os processos ou forças, sendo o trabalho um meio de chegar ao produto, definindo a partir dessa consideração, serviços como atividades econômicas que produzem utilidades relativas a tempo, lugar, forma e benefícios psicológicos.

Considerando que a cocriação de valor, sob a perspectiva da SDL, substitui a entrega tradicional de valor para o cliente (Vargo \& Lusch, 2008a), as proposições de valor estabelecem as conexões e as relações entre os sistemas de serviços (Vargo, 2008). E o valor, na SDL, surge quando os atores ativam e integram os recursos no processo de cocriação, inclusive suas competências e capacidades. As capacidades que facilitam e aumentam os processos de cocriação de valor, sob esta perspectiva, tornam-se, portanto, capacidades estratégicas importantes para a vantagem competitiva da empresa (Karpen, Bove \& Lukas, 2012). Por sua vez, envolve competências e habilidades, em especial o conhecimento. Ou seja, os recursos intangíveis são fundamentais, tendo em vista esta lógica.

Diante disto, a gestão do Capital Relacional (CR) pode ser um fator-chave neste processo, uma vez que CR diz respeito ao conhecimento existente na relação entre a empresa

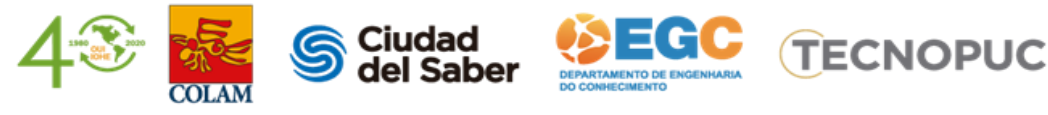


e seus clientes, e seu valor relevante (Bontis, Keow \& Richardson, 2000). Para Kianto, Andreeva e Pavlov (2013), o CR é a capacidade da organização interagir de forma positiva com as partes externas e, com isto, potencializar a criação de riqueza de outros ativos intangíveis, como P\&D, as estruturas da organização e o capital humano.

Alguns autores não compreendem o capital relacional como um recurso, mas sim como uma capacidade que a empresa tem de fazer uso do potencial criado por suas interações (Volkov \& Garanina, 2007). Diante disto, é importante compreender de que forma a gestão do capital relacional pode influenciar este processo, uma vez que diz respeito ao conhecimento existente na relação entre a empresa e seus clientes, e seu valor criado. Desta forma, o objetivo deste estudo é compreender como a gestão do capital relacional pode impulsionar a SDL, de empresas intensivas em conhecimentos, em setores dinâmicos e de alta mobilidade tecnológica.

\section{SERVICE DOMINANT LOGIC}

Conforme Vargo e Morgan (2005), as economias (clássica e neoclássica) possuem foco limitado, por enxergar apenas o valor dos produtos, com base no critério de bens tangíveis. Eles justificam devido a uma mudança de visão de que os "bens não caracterizam a totalidade das trocas" (p.42). Uma nova linha teórica é apresentada pelos autores de Vargo e Lusch (2004a), no artigo 'Evolving to a New Dominant Logic for Marketing', publicado no Journal of Marketing, como 'Service Dominant Logic', onde o serviço configura mais do que o suporte ao produto. Para os autores, os serviços são definidos como a aplicação de conhecimentos especializados por meio de ações, processos e desempenhos para o benefício de outra entidade ou para a própria entidade. Como exemplos, as habilidades, o conhecimento e os processos, arraigados no âmbito do serviço (Payne, Storbacka \& Frow, 2008).

Vargo e Lusch (2008a) denominaram essa lógica como um processo em que se faz algo para uma outra parte, de modo que ele se torna o foco da atenção primária da atividade econômica. Essa lógica se concentra nos benefícios da adição de serviços, onde os produtos são apenas um mecanismo para a prestação de serviços. Concentra-se nas redes de valor e nas proposições de valor (Lüftenegger, Comuzzi \& Grefen, 2017). A SDL caracteriza o serviço 
como o objetivo central da troca econômica e estabelece uma fundamentação teórica para a compreensão de como a empresa, o cliente e outras partes interessadas podem cocriar valores por meio das interações dos serviços entre si. A cocriação de valor, sob a perspectiva da SDL, substitui a entrega tradicional de valor para o cliente (Vargo \& Lusch, 2008a).

Com base nisso, os processos de troca que integram conhecimento e habilidades são focais ao ver a troca como cocriação de valor (Chandler \& Vargo, 2011). Apresentam Vargo e Morgan (2005, p.50), que produtos são de natureza tangível no sentido físico, "mas os consumidores compram serviços que os produtos desempenham para eles, bem como outros intangíveis, como a garantia de uma marca". Na realidade, pelos preceitos da SDL, os consumidores demandam e investem em benefícios e valores (intangíveis).

Os efeitos dos recursos que sofrem as ações transformadoras habilitam as empresas a disponibilizar melhor a proposta de valor em relação a seus competidores (Vargo \& Lusch, 2004).

\section{CRIAÇÃO E COCRIAÇÃO DE VALOR}

A perspectiva tradicional vê a criação de valor como a integração conjunta de recursos pelos múltiplos atores associados a uma troca. Mas a lógica dominante em serviços (Vargo \& Lusch, 2004, 2008) enfatiza o valor advindo da cocriação por múltiplos atores (Prahalad \& Ramaswamy, 2004), em vez de visualizar o valor criado por um único ator. Dessa forma, os processos de troca simultânea que ocorrem entre os atores durante a prestação do serviço, o que Vargo e Lusch (2004) definem como recursos aplicado em benefício de outro ator, pode ser visto como trocas de serviço por serviço.

Para Payne et al. (2008), o encontro de serviço (que é o locus da cocriação), representa séries de interações e transações nas relações entre empresa e cliente. Para os autores, a ideia de maior interatividade entre empresa e cliente e as experiências geradas no encontro, podem representar valor ao consumidor. Valor, na visão de Prahalad e Ramaswamy (2003), se trata de um resultado positivo, derivado da experiência individual do consumidor, em tempo e espaço específicos. Assim sendo, deve contemplar interesses ou utilidades desejadas, relevando a individualidade de cada cliente/consumidor (Debnath, Tandon \& Pointer, 2007). 
O valor é uma variável influenciada "pela percepção global da qualidade do serviço", e exerce impacto na satisfação do consumidor (Alves \& Raposo, 2007, p.574).

$\mathrm{Na}$ SDL entende-se que o valor ocorre no cruzamento entre o prestador e o cliente, e que os produtos podem ser fundamentais para os relacionamentos, mas são itens inanimados de troca que não podem relacionar-se por si mesmos (Vargo \& Lusch, 2004). Nos conceitos da cocriação, o consumidor é endógeno ao processo, pois interage e participa ativamente em conjunto com as organizações (Grönroos, 2011). Essa concepção é reforçada por Prahalad e Ramaswamy (2004), que diferenciam o enfoque tradicional - de se perceber as relações como trocas - para uma visão onde se agregam os consumidores na geração de novos produtos, ideias e valor. O papel do consumidor pode variar de acordo com o tipo e o nível de interação com a empresa (Bitner et al., 1997; Bolton \& Saxena-Iyer, 2009; Broderick, 1999).

Para Vargo e Lusch (2016), a narrativa da cocriação de valor está se transformando em um dos atores que prestam serviços recíprocos, integradores de recursos, que criam valor através de experiências holísticas e significativas em ecossistemas de serviços, governados e avaliados através de seus arranjos institucionais. Os autores admitem que subestimaram a extensão de cocriação de valor em publicações anteriores e que a criação de valor não ocorre apenas através das atividades de um único ator (cliente ou não) ou entre uma empresa e seus clientes, mas entre toda uma série de atores. Ele é criado através da integração de recursos, fornecida por muitas fontes, incluindo uma gama completa de atores públicos e privados voltados para o mercado.

Assim, uma das formas de mensurar as relações entre empresa e seus clientes pode se dar através do Capital Relacional da organização e sua gestão.

\section{CAPITAL RELACIONAL}

Capital Relacional (CR) é uma das dimensões do Capital Intelectual (CI), e refere-se ao relacionamento da organização com seus clientes, entre os membros da organização e parceiros estratégicos, que geram valor para a empresa (Edvinsson \& Malone, 1998). Bontis (1999) compreende que este capital é o conhecimento presente nas relações que as organizações desenvolvem ao longo dos processos de negócios. A forma como as partes interessadas 
compartilham seus conhecimentos, permite à organização agilidade e inovação. O Capital Relacional é quem medeia este processo de compartilhamento (Ngah \& Ibrahim, 2011).

Kianto et al. (2013) consideram que os principais indicadores de valor intangível são vistos em termos de recursos humanos, estruturais e redes de relacionamento. Desta forma, para gerenciá-los, é necessário formular e implementar estratégias que melhor alavanquem estes recursos. Segundo Pablos, (2003) o Capital Relacional é composto pelos conhecimentos que as organizações agregam, advindos da interação com atores externos. Segundo a autora, o valor gerado a partir destas relações é proporcional à longevidade da relação que mantém com seus parceiros e clientes.

Desta forma, o CR é fundamentado no respeito e na confiança mútua existente entre os vários atores, os quais emergem das relações entre as empresas, seus parceiros e clientes (Kale, Singh \& Perlmutter, 2000; Welbourne \& Pardo del Val, 2008). No contexto do CR, confiança diz respeito a confiabilidade e integridade entre os parceiros ativos, atuando como base para relacionamentos de longo prazo entre os parceiros comerciais (Venugopalan, Sisodia \& Rajeevkumar, 2018).

Segundo Venugopalan et al. (2018), as organizações que possuem seu Capital Relacional forte podem obter resultados organizacionais mais promissores. Da mesma forma, o estudo de Hosseini e Owlia (2016) sugerem que os ativos intelectuais possuem relevância estratégica para o $\mathrm{CR}$, pois criam vantagem competitiva a longo prazo, melhor desempenho e maior retorno do investimento. Com isto, desenvolver práticas de gestão do Capital Relacional nas organizações podem ser fundamentais para o desenvolvimento sustentável da mesma, bem como criação de valor.

Alguns estudos afirmam que o Capital Relacional contribui para a inovação, pois muitos dos conhecimentos importantes para inovar não se encontram internamente. Os relacionamentos externos podem ajudar, introduzindo soluções que existam em outros lugares ou combinando conhecimento de diferentes fontes externas (Hargadon \& Sutton, 1999; Kianto, Sáenzb \& Aramburub, 2017). Além disto, o CR pode aumentar a chance de cocriação (Adler \& Kwon, 2002).

A gestão dos ativos intangíveis pertencentes ao Capital Intelectual diz respeito a construção de perspectivas a partir das estratégias de gestão da organização. As organizações

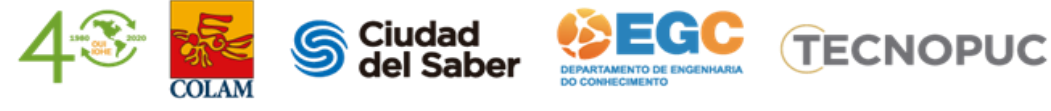


começaram a registrar e gerenciar estes ativos a fim de desenvolver diferenciais em relação aos seus concorrentes, intensificando o valor da gestão do conhecimento (Wiig, 1997).

Sullivan (1998) entende a gestão do Capital Intelectual a partir da criação e extração de valor do conhecimento, dos ativos intelectuais da organização. Algumas práticas de criação de valor podem ser caracterizadas como: a formação dos colaboradores, práticas de compartilhamento do conhecimento, inovações, prospecção de clientes, desenvolvimento de relacionamentos organizacionais e individuais (Stefano, Casarotto Filho, Freitas \& Martinez, 2014).

\section{MÉTODO DO PESQUISA}

Para o desenvolvimento desta pesquisa foi adotada a abordagem qualitativa. Esta abordagem metodológica busca explicar fenômenos, características, comportamentos e necessidades, descobrindo o que é importante para um determinado grupo de pessoas, ao mesmo tempo que entende o que cabe a ser feito. Isto porque os resultados apresentam áreas de consenso no grupo estudado. Possibilitará ao pesquisador construir conhecimentos a partir dos aspectos apresentados pelos sujeitos (Moresi, 2003; Gerhardt \& Silveira, 2009; Merriam, 2009).

A estratégia de investigação utilizada é caracterizada como estudo de casos múltiplo, sendo uma estratégia que envolve mais de um estudo realizado em organização do mesmo segmento (Eisenhardt \& Graebner, 2007). Para os autores, a fim de haver maior consistência neste tipo de estudo, indica-se como número mínimo quatro organizações. A presente pesquisa é composta por uma amostra de seis casos de empresas intensivas em conhecimento, da região sul do Brasil. Todas elas são associadas da Associação Catarinense de Tecnologia (ACATE), que atua há mais de 30 anos em prol do desenvolvimento do setor de tecnologia, do Estado de Santa Catarina. É caracterizado por um ambiente de muita troca de conhecimento.

Os procedimentos para coleta de dados foram definidos por entrevistas em profundidade. O roteiro da entrevista foi construído com questões semiabertas e específicas aos processos a serem investigados. Para a realização das entrevistas semiestruturadas, o pesquisador elabora um roteiro sobre o tema a ser estudado, porém permite que o entrevistado 
fale livremente sobre assuntos que tenham relevância e pertinência ao tema (Gerhardt \& Silveira, 2009).

As entrevistas foram realizadas com 6 CEOs das empresas. Para manter a integridade e credibilidade dos dados, as entrevistas ocorreram com dois pesquisadores. Foi gravada com autorização dos participantes e transcritas.

A análise dos dados foi balizada a partir da análise temática, que se constitui como um método analítico qualitativo de identificação, análise e relato de padrões (temas) encontrados dentro dos dados (Braun \& Clarke, 2006). A análise das entrevistas ocorreu a partir da técnica de análise de conteúdo conforme recomendados por Bardin (2009).

\section{RESULTADOS E DISCUSSÃO}

A partir da análise das entrevistas e conforme modelo teórico apresentado, foi possível perceber a influência da gestão do Capital Relacional nos serviços desenvolvidos pelas empresas entrevistadas. Em parte, pela gestão de ativos intangíveis a partir de perspectivas das estratégias de gestão destas organizações, e do entendimento da criação e extração de valor do conhecimento dos ativos intelectuais da organização e da relação com os clientes.

Baseado nas percepções dos entrevistados, observa-se forte gestão das relações das empresas com seus clientes, stakeholders e a ACATE. Entretanto, o foco principal das empresas está na relação com os clientes.

Então, nosso relacionamento com os clientes é sempre buscando relacionamento de longo prazo e normalmente eles são muito alinhados com o que a gente acha. (Entrevistado empresa B)

A gente é totalmente voltado ao cliente. A gente tem um produto que é tecnologia, é um software, mas a gente vende serviço, né? Por isso que a gente tem tanto foco também numa equipe de atendimento. Por isso é que é a maior equipe. A gente sabe que é através do atendimento, do relacionamento com o cliente que a gente se diferencia, é um dos pilares ali, dos nossos diferenciais. (Entrevistado empresa E)

Algumas práticas de gestão do Capital Relacional observadas foram: criação de eventos para os clientes, em parceria com empresas pares; participação em feiras e eventos internacionais para acompanhar tendências e gerir seus serviços; compartilhamento de 
conteúdo, informações e conhecimentos com os clientes, com objetivo de aumentar o conhecimento sobre seus serviços, a fim de fidelizar e conquistar novos clientes; consultoria e capacitação para o cliente, personalizando os serviços ofertados de acordo com a necessidade do mesmo; apoio, desenvolvimento e educação dos clientes na compra dos serviços.

A partir destas práticas de gestão, percebe-se que a forma como estas empresas relacionam-se com os clientes permite com que os seus produtos possam ser desenvolvidos e aprimorados, a partir da relação durante o serviço prestado. Ainda, melhorias no processo e mesmo do produto ocorrem a partir do feedback do cliente.

Então eis que eu fui lá, morei na granja (propriedade rural), fiquei 70 dias lá programando e aprendendo (...). Não tem nenhum produto que a gente cria aqui que cria da nossa cabeça. Ele é tudo orientado pelo cliente, o nosso cliente é o mandatário. (Entrevistado empresa A).

[Sobre o serviço]: É muito mais implementar a metodologia e validar ela e ir melhorando [com o cliente]. Cada cliente, a gente faz: "Ah, aplica a metodologia, fez um feedback e isso vai melhorando a nossa metodologia, né? Ela foi ganhando várias etapas e perdendo etapas por feedback de clientes. Tipo: "Ah, essa reunião acho que não foi tão útil quanto aquela outra. Ah, está muito grande. Vamos quebrar em dois dias". E a gente vai testando e vai vendo os resultados. [Sobre o produto]: A gente levanta reclamações, comentários, a gente está sempre analisando o feedback final e aí a gente faz melhorias pontuais (Entrevistado empresa B).

A cada dia você está validando novas proposições de produto, variações de produto para conseguir obter mais escala né? Então conforme os parceiros, os clientes, os stakeholders colocam um feedback para você daquilo que você está propondo, você vai retroalimentando isso rapidamente pra, digamos, errar rápido, aprender rápido e corrigir rápido né? (Entrevistado empresa C)

E aí acontece que eles pegam feedback do mercado. Eu não sou um $C E O$ vendedor. Eu não interajo muito com os clientes, eu sou mais da estrutura da coisa. Eu tenho pessoas que são muito melhores do que eu em lidar com pessoas. Então estas pessoas que trazem os inputs para a gente. E quando é um input muito específico, daí eu vou atrás, e converso com a pessoa, pego informação e tudo mais. Mas eu sei das minhas limitações, então eu motivo eles o tempo todo para trazerem isto... "Tá, o que você viu lá? Como foi este projeto? Qual foi a dificuldade? O que teve de legal? O que a gente pode mudar internamente?" 
E nestes inputs que a gente vai fazendo as mudanças internas. (Entrevistado empresa D)

Acontece de eles [clientes] reportarem coisas. A gente tem um canal lá totalmente aberto de comunicação. Por sistema, por escrito que todo mundo pode postar qualquer sugestão, qualquer bug, qualquer coisa que achar. (Entrevistado empresa E)

Na SDL os clientes são endógenos à criação de valor e, como tal, constituem recursos operacionais Vargo e Lusch (2004a; 2008a). Para os autores, o valor é sempre cocriado com os clientes (e outros), em vez de ser criado unilateralmente pela empresa e depois distribuído. Nesta perspectiva, os bens permanecem importantes, mas são identificados como veículos para a prestação de serviços.

Também, identificou-se que a relação com os stakeholders auxilia na organização dos processos internos, qualificando por consequência, a prestação de serviço e o próprio valor do serviço e da organização.

Por a gente ser uma empresa de tecnologia e informação, e a informação é transversal, acabou que a gente se relacionou muito bem com todos os atores, porque a informação que a gente gerava no campo servia pra todos os atores, pra sanidade, pra genética; e a gente começou a ganhar mais mercado. Montamos um banco de dados porque tem muito conhecimento a partir desses dados que a gente pode reverter para o mercado. Construímos um grande benchmarking. (Entrevistado empresa A).

A Acate hoje tem empresas muito grandes associadas. É uma força política, graças a Deus. Porque demorou. Eu acho que o networking é superimportante. A gente conversa com fundos. Tem acesso a fundos porque todo mundo nesse ambiente, e isso, assim, de ser um mercado relevante, começar a se ver como relevante porque está junto para ir para fora (...). Então, agora existe essa organização dos catarinenses lá [São Paulo]. Então, a gente começa a ser mapeado por estar dentro de uma coisa grande né, junto, todo mundo é mais forte. (Entrevistado empresa B).

Para Bontis (1999) e Bontis et al. (2000) o Capital Relacional não é somente o conhecimento presente nas relações com os clientes, é também o conhecimento criado a partir das relações que a organização desenvolve ao longo dos processos de negócios com fornecedores, governo, concorrência e associações. 
Além disto, conforme já exposto, o cerne do CR é a confiança e o respeito que permeiam estas relações. Desenvolvido isto, o serviço pode ser qualificado uma vez que há maior interatividade entre empresa e cliente.

A nossa relação com os clientes é sempre buscando virar parceiro deles depois. Raramente eu tenho cliente que vai ser prestação de serviço única. Então, a gente tem histórico de clientes que viraram parceiros. (Entrevistado empresa B)

Hoje a gente entrega muita informação. No nosso site tem muita informação gratuita... meu, então tá aqui, tá aqui ó a informação gratuita. Informação é para todo mundo, você dá e a gente faz muito isso; não é também por ser muito legal, é porque a gente quer ser autoridade no que a gente está falando, né, é smart business. Então a gente entrega muita informação e isto está fazendo com que nossos clientes vejam a gente como parceiros. (Entrevistado empresa D)

Conforme este último entrevistado, uma maneira de estreitar a relação com o cliente é criar recursos de informação e conhecimento para eles. A criação de valor do serviço é vista por Vargo e Lusch $(2004,2008,2016)$ como a integração conjunta de recursos dos múltiplos atores associados a uma troca, em vez de visualizar o valor criado por um único ator. Além da empresa D, outras apresentaram esta estratégia:

Quer dizer que muito mais do que um serviço com resultado, eu vou capacitar ele para usar essa metodologia e ele vai ter domínio dessa metodologia para usar depois. Então, normalmente os projetos são de sete etapas e eles topam e os produtos dessa consultoria são os serviços que eles querem no final. (Entrevistado empresa B).

A gente tem um blog que a gente posta conteúdo toda semana. Que, de uma certa forma, a gente dispara por e-mail esse conteúdo tanto para clientes quanto para pessoas que deixaram e-mail com a gente, né? E o Facebook acaba sendo também um canal de contato bem relevante. (Entrevistado empresa $\mathrm{E}$ )

A gente pega dados gratuitos, públicos, vamos gerar inteligência e vamos publicar a inteligência. E aí isso começou a dar visibilidade e a gente pegou os dados de Vitória lá, que eles têm $30 \%$ de falta de agendamentos médicos e tudo mais, e beleza, a gente ajuda vocês aí gerando conhecimento, disponibilizamos pro Brasil todo e depois a gente pode chegar em qualquer lugar e mostrar, 'não, a gente é capaz de fazer isso, fazer aquilo' e é isso 
que foi abrindo portas pra chegar nas empresas grandes né? (Entrevistado empresa F)

Nesta linha Bolton (2006) afirma que a Lógica Dominante do Serviço serve como uma espécie de oportunidade na geração de vantagens competitivas por meio da integração de perspectivas e ações, o que pode orientar empresas à criação de novas capacidades e estratégias de trabalho.

Então, por exemplo, tem lá a vertical de energia, de educação, de Cloud Computing, de agrobusiness. Então na vertical de agronegócio, nós estamos com os concorrentes, digamos assim, dentro da mesma vertical. Então, você precisa estar junto com eles, porque tem projetos estruturantes do setor que beneficia todos. Então a forma com que a gente se interfaceia com os concorrentes é um pouco dessa maneira, debatendo na nossa Associação. (Entrevistado empresa A).

A Acate tem a vertical de games. O meu sócio é hoje diretor da vertical, mas quando a gente entrou, ela tinha outro diretor, né? Então, a vertical de Games é uma mobilização, é um encontro de todos os associados do ramo que querem ir lá discutir, fazer ações juntos. Então, com a vertical, a gente fez alguns eventos. (Entrevistado empresa B)

A gente tem, na vertical de energia especificamente, um evento que a gente faz anualmente, a gente está na sétima edição, que chama Energy Show. Não é um evento onde você vai trazer clientes pra vender coisas, cada empresa da vertical convida os seus próprios clientes pra vim aqui ver inovação. Eu brinco que esse é um evento que não é feito onde se vai... que nem outros eventos aonde o público aparece, você tenta criar uma oportunidade com eles. É uma chance de você se relacionar com seu próprio cliente com coadjuvantes. Então sei lá, eu vou trazer 10 clientes, pô, se cada empresa trouxer 10 , eu vou ter 90 coadjuvantes muito interessados. Eles trocam muito. Isso, vamos dizer, viabiliza projetos de uma característica. No nosso caso, se cada um trouxer o seu cliente, que é esse evento, o resultado do evento é diferente, não é um resultado de venda. Porque o meu cliente não é cliente do outro, apesar de ser da mesma empresa. Mas melhora o relacionamento, a imagem da empresa, são coisas diferentes. (Entrevistado empresa D)

A Associação da Acate continua sendo um ponto bastante importante porque existem vários benefícios de tá associado né (...) você está sempre recebendo informações atualizadas do que tá 
acontecendo no mercado, você tem parcerias que vem através disso né? A gente já era fornecedor da Embraer e através da Acate a gente conseguiu fornecer pra um outro lado da empresa que eles não sabiam que a gente existia. E agora a gente tá sendo um case interessante de interação de empresas micro com empresas macro (Entrevistado empresa F).

Ainda, algumas empresas revelam criar e desenvolver conhecimentos a partir da relação com instituições de pesquisa.

Com a Embrapa, agente desenvolve também parceria sempre na troca de dados. Nós entramos com os dados, eles fazem a pesquisa e a gente pega de alguma matéria essa pesquisa e gera uma ferramenta para o produtor [cliente].(Entrevistado empresa A).

Com os relatos apresentados, observa-se que o Capital Relacional destas empresas corroboram com o que Vargo e Lusch (2011) já afirmavam, quando indicam que a existência de mecanismos para facilitar toda integração de recursos e troca de serviços por meio da coordenação dos atores, o papel de vários tipos e arranjos institucionais, tornam-se essenciais para entender a cocriação de valor. Lüftenegger, Comuzzi e Grefen (2017) propõem uma estratégia dominante de serviços para modelos de negócios, onde o ecossistema de serviço serve de ferramenta de um modelo de negócios colaborativo, se concentrando na criação e apropriação de valor em rede, além dos limites de uma organização.

Pode-se observar também nas entrevistas, vários momentos de encontro entre cliente, empresa, stakeholders e parceiros, o que poderia remeter as considerações de Payne et al (2008), onde os "encontros de serviço" seriam o locus da cocriação. Dialogando com descrições de , Fitzsimmons e Fitzsimmons (2005) e Bitner (1990), sobre encontro de serviço, como um triângulo formado pela interação dos interesses do cliente, da organização e do, pessoal da linha de frente, sendo que uma das características singulares dos serviços é a participação ativa do cliente no seu processo de produção, cada momento da verdade representa uma interação entre cliente e um prestador de serviço, indo além quando afirmam que a organização necessita preparar o "ambiente" para que essa interação aconteça e cada um posso desempenhar seu papel.

A gestão do Capital Relacional refere-se a práticas e ações formais, para o estabelecimento e fortalecimento da relação com os clientes, gerando confiança e interação mútua, possibilitanto a criação de valor. Todavia, permanece o questionamento destas práticas 
estarem sendo realizadas de forma empírica e não formalizadas, nas organizações estudadas. Ao longo da entrevistas, nota-se ações que estão presentes nas definições de Capital Relacional, Cocriação de valor e na SDL, como interação, redes de relacionamento, pontos de encontro, processos, feedbacks, relacionamento com o cliente, parceiros, ações desenvolvidas a partir da fala e experiência do cliente e parceiros, nos posicionando como o CR pode pode impulsionar a SDL, de empresas intensivas em conhecimentos, em setores dinâmicos e de alta mobilidade tecnológica. Assim, reforçamos que a criação de práticas conscientes e formais de gestão do capital relacional pode impulsionar a cocriação de valor do serviço.

\section{CONSIDERAÇÕES FINAIS}

Esta pesquisa buscou compreender como a gestão do Capital Relacional pode impulsionar a SDL, de empresas intensivas em conhecimentos. A possibilidade de um serviço proporcionar uma vantagem competitiva sustentável, e um atendimento superior ao da concorrência, faz do serviço uma atividade de caráter estratégico.

Foi possível identificar que a gestão do CR no processo de serviço é capaz de influenciar no valor do serviço prestado e na melhoria dos produtos. Entretanto, este valor é percebido de forma implícita nos relatos dos CEOs e diretores, uma vez que fica claro que o forte relacionamento gera fidelização dos clientes e possibilidade de agregar novos. Além disto, as relações de confiança criadas entre empresa e cliente permite a melhoria dos produtos e serviçes, indicando que este é cocriado através das práticas de gestão do capital relacional, mesmo que de forma informal.

Entretanto, estas percepções dos pesquisadorem não podem ser afirmadas como verdade absoluta, tampouco generalizadas, uma vez que a pesquisa foi realizada apenas com as empresas prestadoras de serviço. Para aprofundar ainda mais este entendimento e mitigando esta limitação da pesquisa, sugere-se que pesquisas futuras investiguem a relação entre gestão do CR e cocriação de valor, sob a perspectiva da SDL, levando em consideração no seu escopo, a percepção dos clientes. A relação entre a percepção da empresa e do cliente pode gerar dados mais fidedignos quanto a cocriação de valor. 
Outro fator relevante aos resultados diz respeito ao pertencimento das empresas pesquisadas em uma Associação. Esta, por sua vez, possui muitas ações voltadas ao desenvolvimento de suas organizações, influenciando o desenvolvimento e aprimoramento do Capital Relacional destas empresas.

Por se tratar de empresas de serviços, a gestão dos recursos intangíveis foi evidenciada e influenciada pelas ações promovidas pela ACATE, pelo relacionamento com stakeholders e clientes. Isto, pois, muitas das inovações, a troca de conhecimento e a própria vantagem competitiva surge do contato e do relacionamento constante no ecossistema onde estão inseridos.

\section{REFERÊNCIAS}

Alves, H., \& Raposo, M. (2007). Conceptual model of student satisfaction in higher education. Total Quality Management, 18(5), 571-588.

Adler, P. S., \& Kwon, S. W. (2002). Social capital: Prospects for a new concept. Academy of management review, 27(1), 17-40.

Brambilla, F. R., \& Damacena, C. (2011). Lógica Dominante do serviço em marketing: estudo dos conceitos e premissas aplicados à educação superior privada na perspectiva docente. Revista Brasileira de Marketing, 10(3), 151-176.

Bardin, L. (2009). Análise de conteúdo. Lisboa: edições, 70, 225.

Bitner, M. J. (1990). Evaluating service encounters: the effects of physical surroundings and employee responses. Journal of marketing, 54(2), 69-82.

Bontis, N., Keow, W. C. C., \& Richardson, S. (2000). Intellectual capital and business performance in Malaysian industries. Journal of intellectual capital.

Bontis, N. (2001). Managing organizational knowledge by diagnosing intellectual capital: framing and advancing the state of the field. In Knowledge management and business model innovation (pp. 267-297). IGI Global.

Bolton, R., \& Saxena-Iyer, S. (2009). Interactive services: a framework, synthesis and research directions. Journal of interactive marketing, 23(1), 91-104.

Braun, V., \& Clarke, V. (2006). Using thematic analysis in psychology. Qualitative research in psychology, 3(2), 77-101.

Chandler, J. D., \& Vargo, S. L. (2011). Contextualization and value-in-context: How context frames exchange. Marketing theory, 11(1), 35-49. 
Debnath, S. C., Tandon, S., \& Pointer, L. V. (2007). Designing business school courses to promote student motivation: An application of the job characteristics model. Journal of management education, 31(6), 812-831.

Edvinsson, L., \& Malone, M. S. (1998). Capital intelectual: descobrindo o valor de sua empresa pela identificação de seus valores internos. São Paulo: Makron Brooks.

Eisenhardt, K. M., \& Graebner, M. E. (2007). Theory building from cases: Opportunities and challenges. Academy of management journal, 50(1), 25-32.

Fitzsimmons, J. A.; \& Fitzsimmons, M.J. (2005). Administração de serviços: operações, estratégias e tecnologia da informação. Porto Alegre: Bookman.

Gerhardt, T. E., \& Silveira, D. T. (2009). Métodos de pesquisa. Plageder.

Grönroos, C. (2011). A service perspective on business relationships: The value creation, interaction and marketing interface. Industrial marketing management, 40(2), 240-247.

Hosseini, M., \& Owlia, M. S. (2016). Designing a model for measuring and analyzing the relational capital using factor analysis. Journal of Intellectual Capital.

Karpen, I. O., Bove, L. L., \& Lukas, B. A. (2012). Linking service-dominant logic and strategic business practice: A conceptual model of a service-dominant orientation. Journal of Service Research, 15(1), 21-38.

Kale, P., Singh, H., \& Perlmutter, H. (2000). Learning and protection of proprietary assets in strategic alliances: Building relational capital. Strategic management journal, 21(3), 217-237.

Kianto, A., Andreeva, T., \& Pavlov, Y. (2013). The impact of intellectual capital management on company competitiveness and financial performance. Knowledge Management Research \& Practice, 11(2), 112-122.

Kianto, A., Sáenz, J., \& Aramburu, N. (2017). Knowledge-based human resource management practices, intellectual capital and innovation. Journal of Business Research, 81, 11-20.

Kon, A. (2004). Economia de serviços: teoria e evolução no Brasil. Editora Campus.

Lüftenegger, E., Comuzzi, M., \& Grefen, P. W. (2017). Designing a tool for service-dominant strategies using action design research. Service Business, 11(1), 161-189.

Lusch, R. F., Vargo, S. L., \& Gustafsson, A. (2016). Fostering a trans-disciplinary perspectives of service ecosystems. Journal of Business Research, 69(8), 2957-2963.

Merriam, S. B. (2009). Qualitative research: A guide to design and implementation. John Wiley \& Sons.

MORESI, E. (2003). Metodologia da Pesquisa (Org.). Universidade Católica de Brasília-UCB.

Ngah, R., \& Ibrahim, A. R. (2011). The Influence of intellectual capital on knowledge sharing: small and medium enterprises' perspective. Communications of the IBIMA.

Pablos, P. O. (2003). Intellectual capital reporting in Spain: a comparative view. Journal of intellectual capital, 4(1), 61-81.

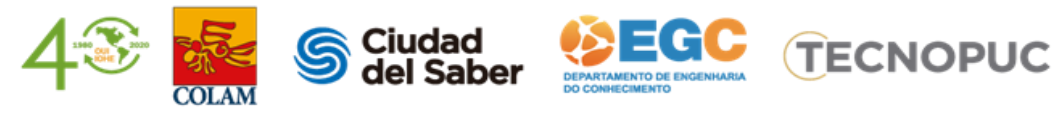


Payne, A. F., Storbacka, K., \& Frow, P. (2008). Managing the co-creation of value. Journal of the academy of marketing science, 36(1), 83-96.

Prahalad, C. K., \& Ramaswamy, V. (2003). The new frontier of experience innovation. MIT Sloan management review, 44(4), 12.

Stefano, N. M., Casarotto Filho, N., Freitas, M. D. C. D., \& Martinez, M. A. T. (2014). Gestão de ativos intangíveis: implicações e relações da gestão do conhecimento e capital intelectual. Perspectivas em Gestão \& Conhecimento, 4(1), 22-37.

Sullivan, P. H. (1998). Profiting from intellectual capital: Extracting value from innovation. John Wiley \& Sons.

Vargo, S. L., \& Lusch, R. F. (2008). Service-dominant logic: continuing the evolution. Journal of the Academy of marketing Science, 36(1), 1-10.

Vargo, S. L., \& Lusch, R. F. (2014). Evolving to a new dominant logic for marketing. In: The Service-Dominant Logic of Marketing. Routlege, p. 21-46

Vargo, S. L., \& Lusch, R. F. (2004a). Evolving to a new dominant logic for marketing. Journal of marketing, 68(1), 1-17.

Vargo, S. L., \& Lusch, R. F. (2004b). The four service marketing myths: remnants of a goodsbased, manufacturing model. Journal of service research, 6(4), 324-335.

Vargo, S. L., \& Morgan, F. W. (2005). Services in society and academic thought: an historical analysis. Journal of macromarketing, 25(1), 42-53.

Venugopalan, M., Sisodia, G. S., \& Rajeevkumar, P. (2018). Business relational capital and firm performance: an insight from Indian textile industry. International Journal of Learning and Intellectual Capital, 15(4), 341-362.

Volkov, D. L., \& Garanina, T. A. (2007). Intellectual capital valuation: Case of Russian companies.

Welbourne, T. M., \& Pardo del Val, M. (2008). Relational capital: strategic advantage for small and medium-size enterprises (SMES) negotiation and collaboration. Los Angeles: Business Management. Recuperado el, 12.

Wiig, K. M. (1997). Knowledge management: an introduction and perspective. Journal of knowledge Management, 1(1), 6-14. 